\title{
Neonatal sepsis-causing bacterial pathogens and outcome of trends of their antimicrobial susceptibility a 20-year period at a neonatal intensive care unit
}

\begin{abstract}
Woo Sun Song, MD ${ }^{1}$, Hye Won Park, MD, PhD², Moon Youn Oh, MD³, Jae Young Jo, MD ${ }^{4}$, Chae Young Kim, MD ${ }^{5}$, Jung Ju Lee, $M D, \mathrm{PhD}^{6}$, Euiseok Jung, $\mathrm{MD}^{3}$, Byong Sop Lee, MD, PhD ${ }^{3}$, Ki-Soo Kim, MD, PhD ${ }^{3}$, Ellen Ai-Rhan Kim, MD, PhD ${ }^{3}$

${ }^{1}$ Department of Medicine, Kyungpook National University, College of Medicine, Daegu, Korea; ${ }^{2}$ Department of Pediatrics, Konkuk University Medical Center, Seoul, Korea; ${ }^{3}$ Division of Neonatology, Department of Pediatrics, Asan Medical Center Children's Hospital, University of Ulsan College of Medicine, Seoul, Korea; ${ }^{4}$ Department of Pediatrics, Gyeongsang National University Hospital, Jinju, Korea; ${ }^{5}$ Department of Pediatrics, Kyung Hee University School of Medicine, Seoul, Korea; 6। \& Mom Pediatrics Clinic, Gangneung, Korea
\end{abstract}

Background: Due to increases in the number of infants born with younger gestational age (GA) and lower birth weight, the incidence of neonatal sepsis is increasing.

Purpose: We investigated the changes in the prevalence of bacterial pathogens, their antimicrobial susceptibility, and sepsis-related mortality during 20 years at a neonatal intensive care unit.

Methods: The study period was divided into two 10-year phases (1998-2007 vs. 2008-2017). Medical records were reviewed to gather data on demographics, causative microbial pathogens, incidence of multidrug-resistant organisms, antimicrobial susceptibility, and rates of sepsis-related mortality.

Results: In both study phases, the most common pathogens for neonatal sepsis were coagulase-negative Staphylococcus (CoNS) (28.6\%) and Enterobacter cloacae (16.1\%) for earlyonset sepsis (EOS, $\leq 72$ hours after birth) and CoNS (54.7\%) and Staphylococcus aureus (12.9\%) for late-onset sepsis (LOS, $>72$ hours after birth). CoNS and S. aureus showed 100\% sensitivity to vancomycin in both phases. The susceptibility of S. aureus to oxacillin increased from $19.2 \%$ to $57.9 \%$ in phase II than phase I. K. pneumonia and E. cloacae showed increases in its susceptibility to gentamicin, cefotaxime and ceftriaxone in phase II than phase I. In both phases, the most common pathogens that caused sepsis-related death were $K$. pneumoniae (18.2\%) and Psendomonas aeruginosa (13.6\%). Sepsis-related mortality rate was higher in infants with GA $<37$ weeks than those with $G A$ over 37 weeks $(P=0.016)$. In addition, the mortality rate of neonatal sepsis caused by gram-negative bacteria was significantly higher than that caused by gram-positive bacteria $(P<0.001)$.

Conclusions: CoNS was the most common pathogen for EOS and LOS. While we found significant changes in antimicrobial sensitivities over time. GA below 37 weeks and gram-negative organisms are associated with mortality rate.
Key words: Neonatal sepsis, Causative organism, Antibiotic sensitivity

\section{Key message}

Question: What is prevalence of bacterial pathogens causing sepsis and their antimicrobial susceptibility over 20 years?

Finding: Coagulase-negative remains most common causative organism. The most common gram-negative organism was Klebsiella pneumonia. The susceptibility of staphylococcus aureus and K. pneumonia showed increased susceptability to oxacillin, cefotaxime and amikacin, gentamicin, respectively.

Meaning: Answers to the question asked is important in choosing antimicrobials and to monitor emergence of multidrug-resistant organisms.

\section{Introduction}

With the development of knowledge, skills, and technologies related to neonatology and perinatology, the mortality rate of hospitalized neonates, including premature infants, in the neonatal intensive care unit (NICU) has been decreasing. However, along with such improvements came increases in the number of infants born with younger gestational age (GA) and lower birth weight as well as morbidities such as bronchopulmonary dysplasia, necrotizing enterocolitis, intraventricular hemorrhage, and retinopathy of prematurity. As a result, we are witnessing increases in the incidence of neonatal sepsis, ${ }^{1-3)}$ which is closely associated with unfavorable long-term neurodevelopmental outcomes including cerebral palsy among preterm infants $^{4)}$ as well as extremely low-birth-weight infants regardless of the causative organism. ${ }^{5}$

The development in neonatal intensive care technologies and the advancement of infection control have reduced the

Corresponding author: Ellen Ai-Rhan Kim, MD. Division of Neonatology, Department of Pediatrics, Asan Medical Center Children's Hospital, University of Ulsan College of Medicine, 88, Olympic-ro 43-gil, Songpa-gu, Seoul 05505, Korea 


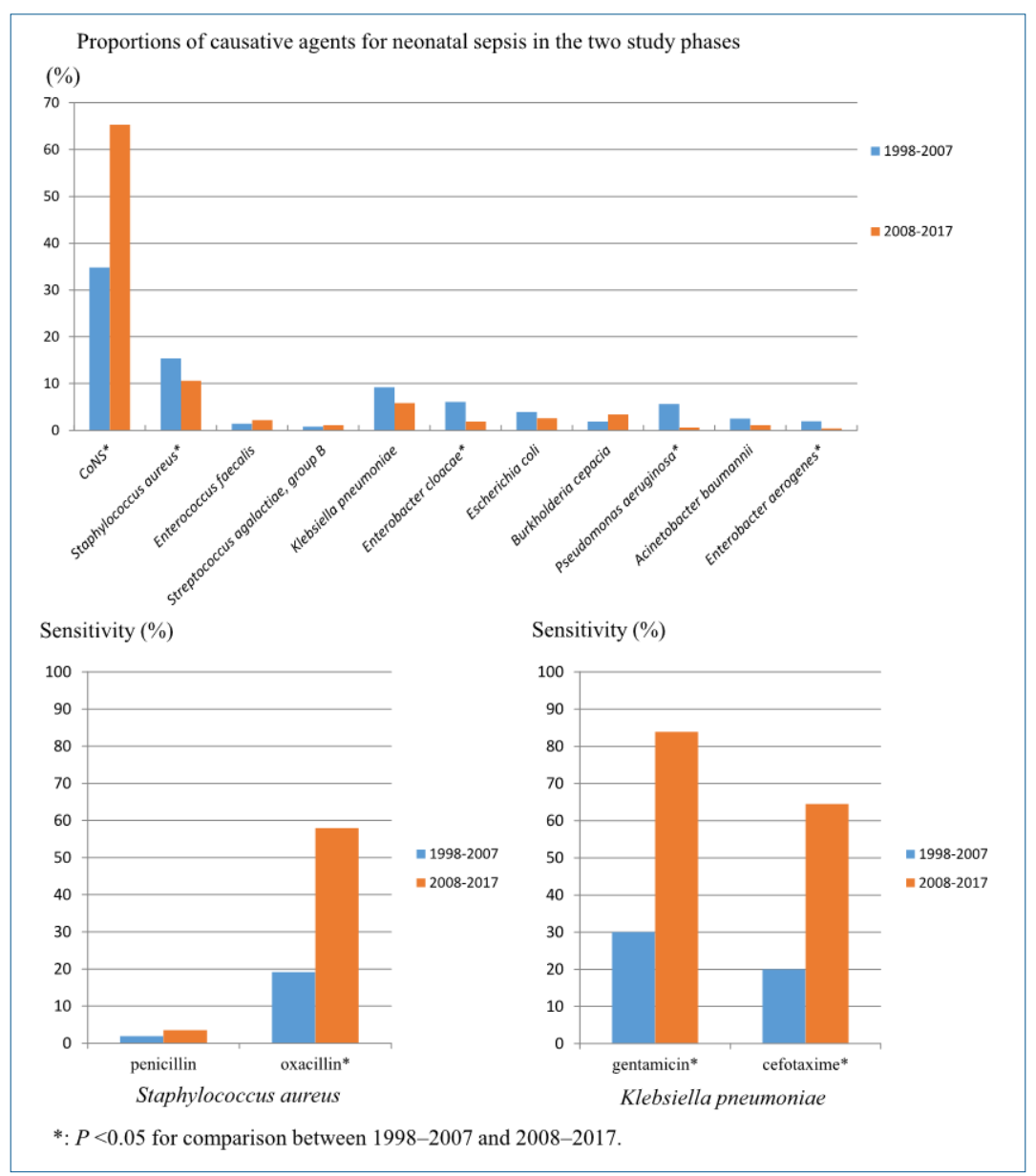

Graphical abstract

incidence rate of sepsis and the resulting mortality; nevertheless, neonatal sepsis still needs to be quickly recognized at NICUs and carefully managed. ${ }^{6,7)}$ In this study, we thoroughly analyzed the records from the last 20 years of our NICU and divided them into two 10-year phases to investigate and compare the causative organisms of neonatal sepsis and identify the changes in antibiotic susceptibility.

\section{Methods}

\section{Study design and population}

We reviewed the medical records of infants with positive blood culture who were admitted to the NICU of Asan Medical Center (Seoul, Korea) between January 1998 and October 2017. For the purpose of comparison, the study period was divided into 2 phases — phase I (January 1998 to December 2007) and phase II (January 2008 to October 2017). We identified the demographic characteristics of the infants, the frequency of sepsis episodes according to birth weight and GA, antibiotic resistance, causative organisms, risk factors associated with death, multidrug resistance, and antimicrobial susceptibility of the cultured grampositive and gram-negative bacteria. Multidrug-resistant microorganisms are defined as acquired nonsusceptibility to at least one agent in 3 or more antimicrobial categories. ${ }^{8)}$ Cases of fungal sepsis and bacterial sepsis resulting from the central lineassociated bloodstream infections were excluded. ${ }^{9)}$

Sepsis occurring within 72 hours after birth and that occurring after 72 hours were defined as early-onset sepsis (EOS) and lateonset sepsis (LOS), respectively. ${ }^{10)}$

Ethical approval for the study was obtained from the Institutional Review Board (IRB) of Asan Medical Center (IRB number: 2017-1159).

\section{Blood specimen}

Blood cultures were obtained when the infants displayed signs indicative of sepsis, including axillary and rectal temperature above $37.5^{\circ} \mathrm{C}$, decrease in tissue perfusion as evidenced by increased in capillary refill time (above 3 seconds), bradycardia (heart rate of under 100 beat per minute), tachycardia (heart rate above 180 beat per minute), apnea (no respiration longer than 20 seconds), tachypnea (respiration rate above 60 rate per minute), metabolic acidosis (arterial blood $\mathrm{pH}<7.2$ ), hypoglycemia (serum glucose $<50 \mathrm{mg} / \mathrm{dL}$ ) and hyperglycemia (serum glucose $>140 \mathrm{mg} / \mathrm{dL})^{1,11-13)}$ Aseptically obtained blood (0.5-1.0 $\mathrm{mL}$ ) was inoculated into a BACTEC PED PLUS/F bottle (Becton Dickinson, Sparks, MD, USA) and a lytic/10 Anaerobic/F bottle. The inoculated blood was sent to a microbiology lab within 24 
hours and was incubated for 5 days at $35^{\circ} \mathrm{Cin}$ a BACTEC 9420 (Becton Dickinson) incubator.

To exclude the possibility of skin contamination or contamination during blood sample collection, we defined gram-positive bacteria including coagulase-negative Staphylococcus (CoNS) as causative pathogens for sepsis only in the following cases: (1) appearance of the clinical features of sepsis included temperature instability, lethargy, poor cry, refusal to suck, prolonged capillary refill time, bradycardia, tachycardia, apnea, tachypnea, hypoglycaemia, hyperglycemia,and metabolic acidosis, ${ }^{1,13)}$ (2) use of antibiotics for more than 5 days after blood culture tests or before death, (3) elevation of C-reactive protein levels (>1 mg/ dL). ${ }^{14)}$

\section{Statistical analysis}

Chi-square test and Fisher exact test were performed using IBM SPSS Statistics ver. 21.0 (IBM Co., Armonk, NY, USA) to compare the frequencies of sepsis-related bacteria between phase I and phase II and the risk factors related to sepsis-related mortality. In addition, Chi-square test and Fisher exact test were used to compare the causative organisms between the 2 phases of the study period. $P$ values smaller than 0.05 were considered statistically significant. Incidence of sepsis is cases per 1,000 births including inborn and outborn infants.

\section{RESULTS}

\section{Characteristics of the infants}

Between January 1998 and October 2017, a total of 14,059 children were admitted to the NICU of Asan Medical Center. Of them, a total of 741 cases of bacteremia were found in the blood cultures of patients who were treated for clinical symptoms of sepsis. Table 1 shows the characteristics of patients.

\section{Incidence of sepsis according to birth weight and GA}

Of the 741 cases of bacteremia, 269 (36.3\%), 140 (18.9\%), 129 (17.4\%), and 203 infants (27.4\%) were birth weight of $<1,000 \mathrm{~g}$ (extremely low birth weight), 1,000-1,499 g (very low birth weight), 1,500-2,499 g (low birth weight), and $\geq 2,500 \mathrm{~g}$ (normal birth weight) (Supplemental Table 1). In terms of the GA, sepsis was observed in 136 infants (18.4\%) with a GA of $\leq 26^{+0}$ weeks, $319(43.0 \%)$ with a GA between 26 weeks and 34 weeks, 100 (13.5\%) with GA between 34 weeks and 37 week, and $186(25.1 \%)$ with a GA of more than 37 weeks (Supplemental Table 2).

\section{Incidence of early- and late-onset neonatal sepsis}

Overall, 876 cases of sepsis were found in 741 infants, and a total of 895 strains were detected in these cases. Fifty-two cases of EOS were found in 50 infants, of whom 2 infants had sepsis more than 2 times. No cases of combined bacteremia were observed. As for LOS, 824 cases were found in 691 newborn infants, in whom 843 strains were detected. Twenty-one cases of combined bacteremia were found in LOS. The incidences of EOS and LOS was $6.2 \%$ and $93.8 \%$, respectively; during the entire study period, the incidence rates of EOS and LOS were 3.8 and 48.8 per 1,000 live births, respectively.

\section{Causative pathogens of neonatal sepsis}

Of the 895 strains cultured from the infants, 674 strains (75.3\%) were gram-positive and CoNS and Staphylococcus aureus were found in 475 (53.0\%) and 112 cases (12.5\%), respectively. Among the gram-negative bacteria, Klebsiella pnew moniae was the most common pathogen (64 cases, 7.1\%), followed by Enterobacter cloacae, E. coli, Burkholderia cepacia, and Pseudomonas aeruginosa (Table 2). Of the CoNS 475 cases, Staphylococcus capitis and Staphylococcus epidermis were found 91 and 347 cases, respectively. S. capitis were identified in 34 cases (7.1\%) in infants with GA under 26 weeks, 43 cases (9.0\%) between 26 weeks and 34 weeks, and 14 cases (2.9\%) over 34 weeks. S. capitis was the most common species in infants with

Table 1. Characteristics of the study patients between the 2 phases

\begin{tabular}{|c|c|c|c|}
\hline Characteristic & Phase I (n=315) (1998-2007) & Phase II (n=426) (2008-2017) & $P$ value \\
\hline Gestational age & $31^{+3}\left(23^{+0}-42^{+1}\right)$ & $30^{+3}\left(22^{+3}-40^{+0}\right)$ & \\
\hline$<26$ weeks & 40/315 (12.7) & $89 / 426(20.9)$ & $0.004^{a)}$ \\
\hline 26-35 weeks & $153 / 315(48.6)$ & $197 / 426(32.9)$ & $<0.001^{a)}$ \\
\hline$\geq 35$ weeks & $122 / 315(38.7)$ & $140 / 426(32.9)$ & $0.099^{a)}$ \\
\hline Male sex & $173 / 315(54.9)$ & $229 / 426(53.8)$ & $0.753^{a)}$ \\
\hline Birth weight (g) & $1,468(469-4,900)$ & $1,290(282-4,125)$ & \\
\hline$<1,500$ & $160 / 315(50.8)$ & $246 / 426(57.7)$ & $0.060^{a)}$ \\
\hline $1,500-2,500$ & $58 / 315(18.4)$ & 73/426 (17.1) & $0.652^{a)}$ \\
\hline$\geq 2,500$ & $97 / 315(30.8)$ & $107 / 426(25.1)$ & $0.087^{a)}$ \\
\hline Delivery mode (cesarean section) & $191 / 315(60.6)$ & 294/426 (69.0) & $0.018^{a)}$ \\
\hline Inborn & $226 / 315(71.7)$ & $407 / 426(85.4)$ & $<0.001^{a)}$ \\
\hline Multiple gestation & $30 / 315(9.5)$ & $174 / 426(27.5)$ & $<0.001^{a)}$ \\
\hline
\end{tabular}

Values are presented as median (range) or number (\%).

a) Indicating chi-square test.

Boldface indicates a statistically significant difference with $P<0.05$. 
Table 2. Comparison of distribution of causative bacteria between the 2 phases

\begin{tabular}{|c|c|c|c|c|c|c|c|c|}
\hline \multirow[b]{2}{*}{ Variable } & \multicolumn{4}{|c|}{ EOS } & \multicolumn{4}{|c|}{ LOS } \\
\hline & $\begin{array}{c}\text { Phase I } \\
(n=35) \\
(1998-2007)\end{array}$ & $\begin{array}{c}\text { Phase II } \\
(n=17) \\
(2008-2017)\end{array}$ & $\begin{array}{c}P \\
\text { value }\end{array}$ & OR $(95 \% \mathrm{Cl})$ & $\begin{array}{c}\text { Phase I } \\
(n=324) \\
(1998-2007)\end{array}$ & $\begin{array}{c}\text { Phase II } \\
(n=519) \\
(2008-2017)\end{array}$ & $\begin{array}{c}P \\
\text { value }\end{array}$ & OR (95\% Cl) \\
\hline Gram-positive bacteria & $26(74.3)$ & $8(47.1)$ & $0.053^{\mathrm{a})}$ & $0.308(0.091-1.039)$ & $212(65.4)$ & $428(82.5)$ & $<0.001^{\text {a) }}$ & $2.485(1.801-3.428)$ \\
\hline CoNS & $11(31.4)$ & $5(29.4)$ & $0.882^{a)}$ & $0.909(0.257-3.218)$ & $114(35.2)$ & $345(66.5)$ & $<0.001^{\mathrm{a})}$ & $3.652(2.728-4.890)$ \\
\hline Staphylococcus aureus & $4(11.4)$ & $0(0)$ & $0.290^{b)}$ & - & $51(15.7)$ & $57(11.0)$ & $0.044^{\mathrm{a})}$ & $0.660(0.440-0.991)$ \\
\hline Enterococcus faecalis & $0(0)$ & $1(5.9)$ & $0.327^{\mathrm{b})}$ & - & $5(1.5)$ & $11(2.1)$ & $0.551^{\text {a) }}$ & $1.381(0.476-4.013)$ \\
\hline $\begin{array}{l}\text { Streptococcus agalactiae, } \\
\text { group B }\end{array}$ & $2(5.7)$ & $2(11.8)$ & $0.589^{b)}$ & $2.200(0.282-17.137)$ & $1(0.3)$ & $4(0.8)$ & $0.654^{\text {b) }}$ & $2.509(0.279-22.545)$ \\
\hline Others ${ }^{c)}$ & $9(25.7)$ & $0(0)$ & $0.023^{b)}$ & - & $41(12.7)$ & $11(2.1)$ & $<0.001^{\mathrm{a})}$ & $0.149(0.076-0.295)$ \\
\hline Gram-negative bacteria & $9(25.7)$ & $9(52.9)$ & $0.053^{\mathrm{a})}$ & $3.250(0.962-10.978)$ & $112(34.6)$ & $91(17.5)$ & $<0.001^{\text {a) }}$ & $0.402(0.292-0.555)$ \\
\hline Klebsiella pneumoniae & $1(2.9)$ & $2(11.8)$ & $0.246^{b)}$ & $4.533(0.381-53.925)$ & $32(9.9)$ & $29(5.6)$ & $0.019^{\mathrm{a})}$ & $0.540(0.320-0.911)$ \\
\hline Enterobacter cloacae & $4(11.4)$ & $1(5.9)$ & $1.000^{b)}$ & $0.484(0.050-4.702)$ & $18(5.6)$ & $9(1.7)$ & $0.002^{\mathrm{a})}$ & $0.300(0.133-0.676)$ \\
\hline Escherichia coli & $1(2.9)$ & $2(11.8)$ & $0.246^{b)}$ & $4.533(0.381-53.925)$ & $13(4.0)$ & $12(2.3)$ & $0.157^{\mathrm{a})}$ & $0.566(0.255-1.257)$ \\
\hline Burkholderia cepacia & $0(0.0)$ & $1(5.9)$ & $0.327^{\mathrm{b})}$ & - & $7(2.2)$ & $17(3.3)$ & $0.344^{\mathrm{a})}$ & $1.534(0.629-3.740)$ \\
\hline Pseudomonas aeruginosa & $2(5.7)$ & $0(0)$ & $1.000^{b)}$ & - & $18(5.6)$ & $3(0.6)$ & $<0.001^{\mathrm{a})}$ & $0.099(0.029-0.338)$ \\
\hline Acinetobacter baumannii & $0(0)$ & $2(11.8)$ & $0.103^{b)}$ & - & $9(2.8)$ & $4(0.8)$ & $0.040^{\mathrm{b})}$ & $0.272(0.083-0.890)$ \\
\hline Serratia marcescens & $0(0)$ & $0(0)$ & & - & $6(1.9)$ & $7(1.3)$ & $0.576^{\mathrm{b})}$ & $0.725(0.241-2.175)$ \\
\hline Enterobacter aerogenes & $1(2.9)$ & $0(0)$ & $1.000^{b)}$ & - & $6(1.9)$ & $2(0.4)$ & $0.060^{\mathrm{b})}$ & $0.205(0.041-1.022)$ \\
\hline Klebsiella oxytoca & $0(0)$ & $0(0)$ & & - & $3(0.9)$ & $5(1.0)$ & $1.000^{\mathrm{b})}$ & $1.041(0.247-4.385)$ \\
\hline Others ${ }^{d)}$ & $0(0)$ & $1(5.9)$ & $0.327^{\text {b) }}$ & - & $0(0.0)$ & $3(0.4)$ & $0.289^{a)}$ & - \\
\hline
\end{tabular}

Values are presented as number (\%).

EOS, early-onset sepsis; LOS, late-onset sepsis; OR, odds ratio; Cl, confidence interval; CoNS, coagulase-negative Staphylococcus.

${ }^{a}$ Chi-square test. ${ }^{\text {b) }}$ Fisher extract test. ${ }^{c}$ Others: Listeria monocytogenes, Streptococcus species (except S. agalactiae), Enterococcus faecium, Bacillus

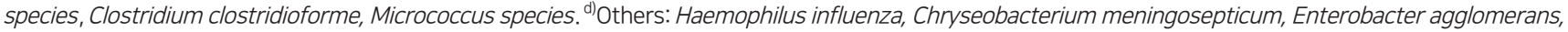
Salmonella group C.

Boldface indicates a statistically significant difference with $P<0.05$.

GA between 26 weeks and 34 weeks. In addition, S. epidermis was confirmed in 56 cases (11.7\%) in infants with GA under 26 weeks, 153 cases (32.2\%) in between 26 weeks and 34 weeks, and 138 cases (29.0\%) over 34 weeks among the 475 cases of CoNS (Supplemental Tables 3,4).

\section{Changes in the prevalence of pathogens between phase I and phase II}

During the study period, the percentage of gram-positive bacteria contributing to sepsis increased from $66.3 \%$ in phase I to $81.2 \%$ in phase II. Particularly, the incidence of CoNS increased from $34.8 \%$ to $65.3 \%(P<0.001)$ and that of S. aureus decreased from $15.4 \%$ to $10.6 \%(P=0.038)$. The incidence of Streptococcus genus (Streptococcus spp.) also significantly decreased from $12.5 \%$ to $1.3 \%(P<0.001)$. Among the gramnegative bacteria, the incidence of $E$. cloacae decreased from $6.1 \%$ to $1.9 \%(P=0.001)$ and that of $P$. aeruginosa decreased from $5.7 \%$ to $0.6 \%(P<0.001)$. The incidence of Enterobacter aerogenes (E. aerogenes) also significantly decreased from $1.9 \%$ to $0.4 \%(P=0.035)$.

With respect to the timing of sepsis onset, the 3 most common organisms isolated in EOS (i.e., CoNS, S. aureus, and Enterobacter cloacae) did not show significant differences in their occurance between the 2 phases. In contrast, the occurance of LOS caused by CoNS was significantly increased in phase II $(P<0.001)$, and those of S. aureus and K. pneumonia were significantly decreased in phase II $(P=0.044$ and 0.019 , respectively). The incidence of CoNS was the most common causative microorganism in both EOS and LOS during the entire study period (Table 2).

\section{Sepsis-related mortality}

Sepsis-related mortality is systemic response to infection leading to death. The most common organisms related to death were K. pneumoniae (18.2\%), P. aeruginosa (13.6\%), S. aureus (13.6\%), S. epidermidis (12.1\%), and E. coli (9.2\%). The mortality rate of neonatal sepsis caused by gram-negative bacteria was significantly higher than that caused by gram-positive bacteria $(19.5 \%$ vs. $3.4 \%, P<0.001)$ (Table 3 , Fig. 1$)$. The mortality rate based on birth weight was $7.1 \%$ and $7.8 \%$ for birth weights $<1,500 \mathrm{~g}$ and $\geq 1,500$, respectively $(P=0.706)$. And $7.1 \%$ and $8.1 \%$ for birth weights below 2,500 g, and birth weights over $2,500 \mathrm{~g}$, respectively $(P=0.627)$. In respective to GA, the mortality was observed in 50 of 554 infants $(9.0 \%)$ with GA below 37 weeks and 16 of 341 infants (4.7\%) with GA over 37 weeks $(P=0.016)$. In addition, mortality rate due to methicillin-resistant Staphylococcus aureus (MRSA) and extended spectrum $\beta$-lactamases (ESBL)-producing Enterobacteriaceae sepsis were $9.0 \%$ and $21.9 \%$, respectively (Table 4).

\section{Changes in the susceptibility to antibiotics}

The susceptibility of the gram-positive and gram-negative 
Table 3. Comparison of distribution of mortality between the 2 phases

\begin{tabular}{|c|c|c|c|c|}
\hline Microorganism & Phase I (1998-2007) & Phase II (2008-2017) & $P$ value & OR $(95 \% \mathrm{Cl})$ \\
\hline Mortality & $39 / 315$ & $27 / 426$ & & \\
\hline Klebsiella pneumoniae & $5 / 33(15.2)$ & $7 / 31(22.6)$ & $0.447^{\mathrm{a})}$ & $1.633(0.458-5.819)$ \\
\hline ESBL-producing & $2 / 5(40.0)$ & $5 / 7(71.4)$ & & \\
\hline Pseudomonas aeruginosa & $7 / 20(35.0)$ & $2 / 3(66.7)$ & $0.538^{b)}$ & $3.714(0.284-48.545)$ \\
\hline Staphylococcus aureus & $6 / 55(10.9)$ & $3 / 57(5.3)$ & $0.317^{b)}$ & $0.454(0.108-1.913)$ \\
\hline Staphylococcus epidermidis & $5 / 122(5.0)$ & $3 / 125(1.2)$ & $0.047^{b)}$ & $0.234(0.055-0.997)$ \\
\hline Escherichia coli & 4/14 (28.6) & $2 / 14(14.3)$ & $0.648^{b)}$ & $0.417(0.063-2.768)$ \\
\hline Enterobacter cloacae & $3 / 22(13.6)$ & $1 / 10(10.0)$ & $1.000^{b)}$ & $0.704(0.064-7.742)$ \\
\hline Mortality of EOS & $7 / 33(21.2)$ & $5 / 17(29.4)$ & $0.728^{b)}$ & $1.548(0.407-5.887)$ \\
\hline Mortality of LOS & $32 / 282(11.3)$ & $22 / 409(5.4)$ & $0.004^{a)}$ & $0.444(0.252-0.782)$ \\
\hline Total mortality & $39 / 315(12.4)$ & $27 / 426(6.3)$ & $0.004^{\mathrm{a})}$ & $0.479(0.286-0.801)$ \\
\hline
\end{tabular}

Values are presented as number (\%).

$\mathrm{OR}$, odds ratio; $\mathrm{Cl}$, confidence interval; ESBL, extended spectrum $\beta$-lactamases; EOS, early-onset sepsis; LOS, late-onset sepsis.

${ }^{a)}$ Chi-square test. ${ }^{\text {b) }}$ Fisher extract test.

Boldface indicates a statistically significant difference with $P<0.05$.
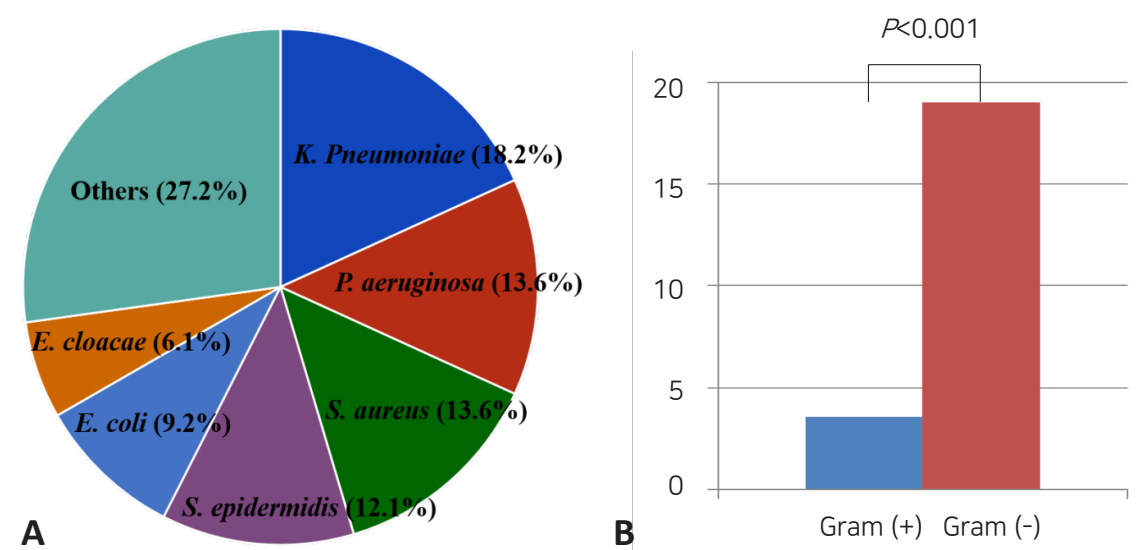

Fig. 1. Comparison of causative agents of neonatal sepsis resulting in death. (A) Proportions of microorganisms related to death. (B) Comparison between the proportions of gram-positive and gram-negative organisms associated with mortality.

bacteria to antibiotics was compared between phase I and phase II. The susceptibility of $S$. aureus to oxacillin increased from $19.2 \%$ to $57.9 \%$ in phase II from phase I $(P<0.001)$. There was no statistical difference in the susceptibility of CoNS to oxacillin between 2 phases $(P=1.000)$ (Table 5). Vancomycin-resistant strains were not detected in gram-positive bacteria including $S$. aureus and CoNS during the study period.

Among the gram-negative bacteria, K. pneumonia showed increases in its susceptibility to gentamicin, cefotaxime and ceftriaxone in phase II than phase I (Table 5). E. cloacae showed increases in its susceptibility to gentamicin, cefotaxime, and ceftriaxone in phase II than phase I $(P<0.001, P=0.007, P=$ 0.018 ) (Table 5 ). The susceptibility of $E$. coli to gentamicin, cefotaxime and ceftriaxone showed no statistical difference between 2 phases (Table 5). Carbapenem-resistance was not observed in K. pneumonia, E. coli, B. species, and Enterobacter cloacae.

\section{Discussion}

In Korea, the number of infants admitted to the NICU has been increasing during the past 20 years owing to the increase in the number of births of premature infants and very low birth weight infants. ${ }^{15)}$ In addition, the risk of neonatal sepsis resulting from invasive treatment and increased length of hospital stay has been increasing as well. ${ }^{16)}$ In particular, CoNS emerged as the foremost pathogens of neonatal sepsis in developed countries. ${ }^{16,17)}$ Accordingly, our current study also showed that CoNS was the most common pathogen in EOS as well as LOS. Despite the hospital infection control, CoNS remains the most common pathogen, which is likely due to the increased number of sick neonates and increased number of very low birth weight infants that require invasive procedures and increased hospital days. ${ }^{16)}$

Previous studies have reported varying incidence rates of EOS. Bhat et al. ${ }^{18)}$ reported a high incidence of 104.6 per 1,000 patients, whereas Resch et al. ${ }^{19)}$ reported a low incidence of 0.8 per 1,000 patients. In our current study, the incidence of EOS 
was 3.8 per 1,000 patients during the entire study period. The incidence of EOS decreased from 5.2 per 1,000 infants in the phase I (1998 to 2007) to 2.6 per 1,000 infants in the phase II (2008 to 2017).

In a study by Cohen-Wolkowiez et al., ${ }^{20)}$ gram-positive bac-

Table 4. Analysis of associated factors for mortality

\begin{tabular}{lllc}
\hline Factor & Episodes & $P$ value & OR (95\% Cl) \\
\hline GA (wk) & & $0.016^{\text {a) }}$ & $0.496(0.278-0.886)$ \\
$<37$ & $50 / 554(9.0)$ & & \\
$\geq 37$ & $16 / 341(4.7)$ & & \\
Birth weight (g) & & & \\
$<1,500$ & $36 / 508(7.1)$ & $0.706^{\text {a) }}$ & $1.102(0.666-1.823)$ \\
$\geq 1,500$ & $30 / 387(7.8)$ & & \\
$<2,500$ & $47 / 660(7.1)$ & $0.627^{\text {a) }}$ & $1.147(0.659-1.998)$ \\
$\geq 2,500$ & $19 / 235(8.1)$ & & \\
Gram-positive bacteria & $23 / 674(3.4)$ & $<0.001$ & $6.838(4.014-11.649)$ \\
Gram-negative bacteria & $43 / 221(19.5)$ & & \\
MRSA mortality rate & $6 / 66(9.0)$ & & \\
ESBL ${ }^{\text {b) }}$ mortality rate & $9 / 41(21.9)$ & & \\
\hline
\end{tabular}

Values are presented as number (\%).

$\mathrm{OR}$, odds ratio; $\mathrm{Cl}$, confidence interval; $\mathrm{GA}$, gestational age; MRSA, methicillin-resistant Staphylococcus aureus; ESBL, extended spectrum $\beta^{-}$ lactamases.

${ }^{\text {a) }}$ Chi-square test. ${ }^{\text {b) } E S B L: ~} 28$ cases of Klebsiella pneumoniae, 12 cases of Escherichia coli, 1 case of Klebsiella oxytoca; infants with 6 cases of $K$ pneumoniae and 3 cases of $E$. coli died, respectively. teria accounted for $62 \%$ of all pathogens in EOS and the major pathogens included group B Streptococcus (GBS), S. aureus, and CoNS. Of note, the incidence of GBS as the causative organism for EOS increased in the latter phase in our study, resulting in an incidence of 0.28 per 1,000 live births during the entire study period; this result is in line with the reports from Western countries ${ }^{21)}$ in which the incidence rate of GBS has been reported as 0.29 per 1,000 live births. In contrast, a report from $\mathrm{Japan}^{22)}$ showed a relatively lower incidence of 0.08 per 1,000 live births. On the other hand, the mortality rates of EOS and LOS have been reported to be $1.7 \%-22.9 \%$ and $4.0 \%-18.0 \%$, respectively. ${ }^{19-21,23,24)}$ The results of our study are in line with those reports, as the mortality rates of EOS and LOS were $12.4 \%$ and $6.3 \%$, respectively.

During the entire study period, the most common sepsiscausing pathogens were S. epidermidis and S. aureus. Overall, $75 \%$ of the pathogens showed sensitivities to trimethoprimsulfamethoxazole and $100 \%$ of the pathogens were sensitive to vancomycin. When encountering multidrug-resistant $S$. epidermidis and $S$. aureus, trimethoprim-sulfamethoxazole could be used as an alternative antimicrobial agent or adjuvant therapy, although its use among neonate is very limited.

The susceptiblilty of CoNS to antibiotics reported by Ozkan et al. ${ }^{25)}$ was similar to that reported in this study. With regard to sepsis-causing gram-negative bacteria, K. pneumoniae and E. coli including ESBL-producing isolates showed 100\% susceptiblilty

Table 5. Comparison of antibiotics susceptibility of causative agents between the 2 phases

\begin{tabular}{|c|c|c|c|c|}
\hline Microorganism & $\begin{array}{c}\text { Phase I } \\
(1998-2007)\end{array}$ & $\begin{array}{c}\text { Phase II } \\
(2008-2017)\end{array}$ & $P$ value & OR $(95 \% \mathrm{Cl})$ \\
\hline \multicolumn{5}{|c|}{ Gram-positive bacteria } \\
\hline \multicolumn{5}{|c|}{ Staphylococcus aureus } \\
\hline Penicillin & $1 / 52(1.9)$ & $2 / 57(3.5)$ & $1.000^{b)}$ & $1.855(0.163-21.076)$ \\
\hline Cefotaxime & $12 / 52(23.1)$ & $8 / 12(66.7)$ & $0.006^{\mathrm{b})}$ & $6.667(1.707-26.042)$ \\
\hline Oxacillin & 10/52 (19.2) & $33 / 57(57.9)$ & $<0.001^{\text {a) }}$ & $5.775(2.426-13.746)$ \\
\hline \multicolumn{5}{|l|}{ CoNS } \\
\hline Penicillin & $1 / 114(0.9)$ & 0/350(0.0) & $0.246^{\mathrm{b})}$ & 0.991 (0.974-1.008) \\
\hline Cefotaxime & $3 / 105(2.9)$ & $1 / 51(2.0)$ & $1.000^{b)}$ & $0.680(0.069-6.704)$ \\
\hline Oxacillin & $3 / 114(2.6)$ & $10 / 350(2.9)$ & $1.000^{b)}$ & $1.088(0.294-4.025)$ \\
\hline \multicolumn{5}{|c|}{ Gram-negative bacteria } \\
\hline \multicolumn{5}{|c|}{ Klebsiella pneumoniae } \\
\hline Gentamicin & 9/30 (30.0) & 26/31 (83.9) & $<0.001^{\text {a) }}$ & $12.133(3.528-41.729)$ \\
\hline Cefotaxime & $6 / 30(20.0)$ & $20 / 31(64.5)$ & $0.001^{a)}$ & $7.273(2.284-23.160)$ \\
\hline Ceftriaxone & $6 / 30(20.0)$ & $16 / 20(80.0)$ & $<0.001^{a)}$ & $16.000(3.889-65.830)$ \\
\hline \multicolumn{5}{|c|}{ Enterobacter cloacae } \\
\hline Gentamicin & $5 / 20(25.0)$ & $10 / 10(100.0)$ & $<0.001^{\text {a) }}$ & $0.250(0.117-0.534)$ \\
\hline Cefotaxime & $5 / 20(25.0)$ & $8 / 10(80.0)$ & $0.007^{b)}$ & $12.000(1.885-76.376)$ \\
\hline Ceftriaxone & $5 / 20(25.0)$ & $5 / 6(83.3)$ & $0.018^{\mathrm{b})}$ & $15.000(1.397-161.045)$ \\
\hline \multicolumn{5}{|l|}{ Escherichia coli } \\
\hline Gentamicin & $5 / 14(35.7)$ & $7 / 14(50.0)$ & $0.704^{a)}$ & $1.800(0.396-8.182)$ \\
\hline Cefotaxime & $7 / 13(53.8)$ & $6 / 14(42.9)$ & $0.568^{\mathrm{a})}$ & $0.643(0.141-2.938)$ \\
\hline Ceftriaxone & $7 / 14(50.0)$ & $2 / 5(40.0)$ & $1.000^{b)}$ & $0.667(0.084-5.301)$ \\
\hline
\end{tabular}

Values are presented as number (\%).

$\mathrm{OR}$, odds ratio; $\mathrm{Cl}$, confidence interval; CoNS, coagulase-negative Staphylococcus.

${ }^{\text {a) }}$ Chi-square test. ${ }^{\text {b) }}$ Fisher extract test.

Boldface indicates a statistically significant difference with $P<0.05$. 
to imipenem. In this study, there were 12 and 9 cases of ESBLproducing $K$. pneumoniae and E. coli, respectively. In addition, the susceptiblilty to amikacin was above $85 \%$ in the phase II of the study period.

As for multidrug-resistant organisms, MRSA was identified in 66 patients during the entire study period. Of these, 6 infants including 3 VLBW infants died, resulting in a mortality rate of 9.0\%. The mortality rate in patients with MRSA sepsis with birth weights less than $1,500 \mathrm{~g}$ was $9.6 \%$, which is lower than the $26.1 \%$ reported by Shane et al. ${ }^{26)}$

ESBL-producing microbes are also a type of multidrug-resistant bacterium that can unexpectedly spread rapidly in the NICU. ${ }^{27)}$ During the entire study period, 9 patients died and the mortality from sepsis caused by ESBL-producers was $21.9 \%$. Sharma et al. ${ }^{28)}$ reported that the mortality rate of infants infected with ESBL-producing microbes was as high as 38.6\%. In our study, we did not find significant differences between the 2 study phases in terms of the incidence and mortality of sepsis caused by ESBL-producers; however, we found 2 cases of EOS during phase II, resulting in an incidence of $11.7 \%$, which is lower than the $44.7 \%$ reported by Sharma et al. ${ }^{28)}$

CoNS was the single most common organism that caused neonatal sepsis in our unit. Acknowledging this fact, our medical staff practice strict hand-washing, exercise aseptic procedures in the care of the central lines, promote early breast milk feeding, and utilize other preventive measures to decrease the incidence of sepsis; yet, we are still battling against sepsis, especially those related to CoNS. Due to the widespread resistance to beta-lactam in CoNS and MRSA, vancomycin is used as the first-line antibiotics for LOS in our unit. The use of vancomycin is strictly controlled by the hospital infection control team and we have yet to encounter cases of sepsis caused by vancomycinresistant organisms. Dalal et al. ${ }^{29)}$ reported that cyclic use of antibiotics is effective in preventing the emergence of multidrugresistant bacteria. Accordingly, we have also practiced cyclic use of antibiotics (e.g., cefotaxime to amikacin, amikacin to tazobactam) for LOS, and have yet to observe an emergence of multidrug-resistant organisms during our 20-year history of antibiograms.

This study has limitations. As a retrospective study from a single tertiary NICU, it would be difficult to compare the results in between other NICUs of variable level of intensities. ${ }^{30)}$

In conclusion, we herein report the trends in antimicrobial susceptibility and bacterial pathogens causing neonatal sepsis during a 20 -year period at a single neonatal care unit. Overall, the results of the etiologic organisms were similar to that of the Korean national registry of neonatal sepsis. ${ }^{31,32)}$ However, as the incidence of multidrug-resistant microorganisms-especially thoserelated to ESBL-producers-is increasing both in and out of the NICU, neonatologists must be more alert in dealing with such organisms when they become more frequently isolated, especially among delivering mothers.

\section{Footnotes}

Conflicts of interest: No potential conflict of interest relevant to this article was reported.

Funding: This study received no specific grant from any funding agency in the public, commercial, or not-for-profit sectors.

ORCID:

Woo Sun Song (1) https://orcid.org/0000-0001-7894-5213

Hye Won Park @ https://orcid.org/0000-0002-2669-3621

Moon Youn Oh $\odot$ https://orcid.org/0000-0003-1444-6495

Jae Young Jo @ https://orcid.org/0000-0002-3654-067X

Chae Young Kim (1) https://orcid.org/0000-0002-9905-6519

Jung Ju Lee @ https://orcid.org/0000-0001-7152-6294

Euiseok Jung $\odot$ https://orcid.org/0000-0003-0693-5627

Byong Sop Lee @ https://orcid.org/0000-0002-1347-4200

Ki-Soo Kim $\odot$ https://orcid.org/0000-0003-1547-5220

Ellen Ai-Rhan Kim @ https://orcid.org/0000-0002-9859-3021

\section{References}

1. Shim GH, Kim SD, Kim HS, Kim ES, Lee HJ, Lee JA, et al. Trends in epidemiology of neonatal sepsis in a tertiary center in Korea: a 26-year longitudinal analysis, 1980-2005. J Korean Med Sci 2011;26:284-9.

2. Bizzarro MJ, Raskind C, Baltimore RS, Gallagher PG. Seventy-five years of neonatal sepsis at Yale: 1928-2003. Pediatrics 2005;116:595-602.

3. Moore MR, Schrag SJ, Schuchat A. Effects of intrapartum antimicrobial prophylaxis for prevention of group-B-streptococcal disease on the incidence and ecology of early-onset neonatal sepsis. Lancet Infect Dis 2003;3:201-13.

4. Adams-Chapman I, Stoll BJ. Neonatal infection and long-term neurodevelopmental outcome in the preterm infant. Curr Opin Infect Dis 2006; 19:290-7.

5. Stoll BJ, Hansen NI, Adams-Chapman I, Fanaroff AA, Hintz SR, Vohr $B$, et al. Neurodevelopmental and growth impairment among extremely low-birth-weight infants with neonatal infection. JAMA 2004;292:235765.

6. Bae YM, Bae CW. The changes in the mortality rates of low birth weight infant and very low birth weight infant in Korea over the past 40 years. J Korean Med Sci 2004; 19:27-31.

7. Goldenberg RL, Culhane JF, Iams JD, Romero R. Epidemiology and causes of preterm birth. Lancet 2008;371:75-84.

8. Siegel JD, Rhinehart E, Jackson M, Chiarello L; Healthcare Infection Control Practices Advisory Committee. Management of multidrugresistant organisms in health care settings, 2006. Am J Infect Control 2007;35(10 Suppl 2):S165-93.

9. Bell T, O'Grady NP. Prevention of central line-associated bloodstream infections. Infect Dis Clin North Am 2017;31:551-9.

10. Stoll BJ, Hansen N. Infections in VLBW infants: studies from the NICHD Neonatal Research Network. Semin Perinatol 2003;27:293-301.

11. Camacho-Gonzalez A, Spearman PW, Stoll BJ. Neonatal infectious diseases: evaluation of neonatal sepsis. Pediatr Clin North Am 2013;60: 367-89.

12. Gerdes JS. Clinicopathologic approach to the diagnosis of neonatal sepsis. Clin Perinatol 1991;18:361-81.

13. Sankar MJ, Agarwal R, Deorari AK, Paul VK. Sepsis in the newborn. Indian J Pediatr 2008;75:261-6.

14. Hyde TB, Hilger TM, Reingold A, Farley MM, O'Brien KL, Schuchat A, et al. Trends in incidence and antimicrobial resistance of early-onset sepsis: population-based surveillance in San Francisco and Atlanta. Pediatrics 
2002;110:690-5.

15. Shin SM. Should we regularly evaluate the neurodevelopmental status of moderate and late preterm infants? Clin Exp Pediatr 2020;63:217-8.

16. Kim JK, Chang YS, Sung S, Ahn SY, Park WS. Trends in the incidence and associated factors of late-onset sepsis associated with improved survival in extremely preterm infants born at 23-26 weeks' gestation: a retrospective study. BMC Pediatr 2018;18:172.

17. Mularoni A, Madrid M, Azpeitia A, Valls i Soler A. The role of coagulasenegative staphylococci in early onset sepsis in a large European cohort of very low birth weight infants. Pediatr Infect Dis J 2014;33:e121-5.

18. Bhat YR, Lewis LE, K E V. Bacterial isolates of early-onset neonatal sepsis and their antibiotic susceptibility pattern between 1998 and 2004: an audit from a center in India. Ital J Pediatr 2011;37:32.

19. Resch B, B R, NH. Comparison Between Pathogen Associated Laboratory and Clinical Parameters in Early-Onset Sepsis of the Newborn. Open Microbiol J 2016;10:133-9.

20. Cohen-Wolkowiez M, Moran C, Benjamin DK, Cotten CM, Clark RH, Benjamin DK Jr, et al. Early and late onset sepsis in late preterm infants. Pediatr Infect Dis J 2009;28:1052-6.

21. Weston EJ, Pondo T, Lewis MM, Martell-Cleary P, Morin C, Jewell B, et al. The burden of invasive early-onset neonatal sepsis in the United States, 2005-2008. Pediatr Infect Dis J 2011;30:937-41.

22. Matsubara K, Hoshina K, Suzuki Y. Early-onset and late-onset group B streptococcal disease in Japan: a nationwide surveillance study, 20042010. Int J Infect Dis 2013; 17:e379-84.

23. Greenberg RG, Kandefer S, Do BT, Smith PB, Stoll BJ, Bell EF, et al. Lateonset sepsis in extremely premature infants: 2000-2011. Pediatr Infect Dis J 2017;36:774-9.

24. Testoni D, Hayashi M, Cohen-Wolkowiez M, Benjamin DK Jr, Lopes RD, Clark RH, et al. Late-onset bloodstream infections in hospitalized term infants. Pediatr Infect Dis J 2014;33:920-3.
25. Ozkan H, Cetinkaya M, Koksal N, Celebi S, Hacimustafaoglu M. Culture-proven neonatal sepsis in preterm infants in a neonatal intensive care unit over a 7 year period: coagulase-negative Staphylococcus as the predominant pathogen. Pediatr Int 2014;56:60-6.

26. Shane AL, Hansen NI, Stoll BJ, Bell EF, Sanchez PJ, Shankaran S, et al. Methicillin-resistant and susceptible Staphylococcus aureus bacteremia and meningitis in preterm infants. Pediatrics 2012;129:e914-22.

27. Sumer S, Turk Dagi H, Findik D, Arslan U, Aktug Demir N, Ural O, et al. Two outbreaks of ESBL-producing Klebsiella pneumoniae in a neonatal intensive care unit. Pediatr Int 2014;56:222-6.

28. Sharma D, Kumar C, Pandita A, Pratap OT, Dasi T, Murki S. Bacteriological profile and clinical predictors of ESBL neonatal sepsis. J Matern Fetal Neonatal Med 2016;29:567-70.

29. Dalal P, Gathwala G, Gupta M, Jasbir S. Bacteriological profile and antimicrobial sensitivity pattern in neonatal sepsis: a study form north india. Int J Res Med Sci 2017;5:1541-5.

30. Abdellatif M, Al-Khabori M, Rahman AU, Khan AA, Al-Farsi A, Ali K. Outcome of late-onset neonatal sepsis at a tertiary hospital in Oman. Oman Med J 2019;34:302-7.

31. Lee SM, Chang M, Kim KS. Blood culture proven early onset sepsis and late onset sepsis in very-low-birth-weight infants in Korea. J Korean Med Sci 2015;30 Suppl 1:S67-74.

32. Kim EAR. Antimicrobial management of neonatal sepsis. J Korean Neonatol 2012;19:53-64.

How to cite this article: Song WS, Park HW, Oh MY, Jo JY, Kim CY, Lee JJ, et al. Neonatal sepsis-causing bacterial pathogens and outcome of trends of their antimicrobial susceptibility a 20year period at a neonatal intensive care unit. Clin Exp Pediatr 2022;65:350-7. https://doi.org/10.3345/cep.2021.00668 